\title{
Networks Mobilized to Access Key Resources at Early Stages of Biotech Firms: A Comparative Analysis in Two Moderately Innovative Countries
}

\author{
GUIDO CAPALDO*, MARGARIDA FONTES ${ }^{* *}, \dagger$, \\ LORELLA CANNAVACCIUOLO*, PIERLUIGI RIPPA* \& \\ CRISTINA SOUSA ${ }^{\dagger}$

\begin{abstract}
*Department of Industrial Engineering, University Federico II of Naples, Naples, Italy, ${ }^{* *}$ Laboratório Nacional de Energia e Geologia, Lisboa, Portugal, 'DINAMIA’CET-IUL, Lisboa, Portugal
\end{abstract}

(Received April 2014; accepted June 2014)

\begin{abstract}
This paper investigates the networking behaviour of biotechnology start-ups in peripheral locations. The aim is to understand whether the conditions found in this type of environment introduce some specificities in the networking process, namely in network building and early mobilization to access key resources. The paper compares biotechnology start-ups in Portugal and in Southern Italy, focusing on relationships with research organizations and on the relevance assumed by international connections, and investigating the role played by entrepreneurs' personal networks. The research identified some common features that diverge from the typical biotechnology start-up behaviour and can be regarded as firms' adaptive responses to the conditions faced. Notwithstanding the frequent presence of close connections with local research organizations-that often play functions that go much beyond that of a knowledge source-the local environment is a lesser determinant for a substantial proportion of firms than would be expected in start-ups. A distinctive feature of these firms is an extensive reliance on foreign sources, for different purposes and from the very early stages. Entrepreneurs' personal networks are found to be instrumental, both to identify and obtain knowledge in the vicinity and to support the establishment of more complex distant relationships.
\end{abstract}

Correspondence Address: Pierluigi Rippa, Department of Industrial Engineering, University Federico II of Naples, P.le Tecchio 80, 80135 Naples, Italy. Email: pierluigi.rippa@unina.it

This article was originally published with errors. This version has been corrected. Please see Erratum (http://dx.doi.org/10.1080/09654313.2014.950807) 